\title{
A qualitative analysis of the 'experiential learning' of business school students and graduates through their participation in The University of Manchester's annual business start-up competition
}

\author{
Prateek Pralhad Kulkarni ${ }^{1}$
}

Received: 13 December 2018 / Revised: 10 July 2019 / Accepted: 11 July 2019 /

Published online: 23 August 2019

(c) The Author(s) 2019

\begin{abstract}
Business model tools are viewed with importance by entrepreneurs and also by the academic community that offer entrepreneurship education. Business schools teach business model tools with great importance, so that the students can understand their usefulness and also apply these to their ideas. Students pursuing courses on entrepreneurship and related business programs are taught about these tools by presenting to them case studies where these tools are applied, etc. However, it is of question as to how much importance do the students give to these tools when they are being taught in their courses, and also, whether they get a chance to experience the usage of these business model tools. Business start-up competitions play an important role in giving students an opportunity to apply the business model tools to their own ideas, explore their (business model tools') usefulness and also gain an experiential understanding of using these. It is important to analyse as to whether these business school students are able to learn through the experience of using these tools for their business ideas in the competition. In this paper, it is examined, as to whether business start-up competitions provide experience to the business school students of using the business model tools and whether through these competitions, students of the University of Manchester feel more confident of knowing how to use these tools for entrepreneurship. The particular business idea competition that is a focus of this paper is the Venture Further competition of 2017.
\end{abstract}

Keywords Entrepreneurship education · Experiential learning · Venture Further $2017 \cdot$ Entrepreneurial activities · Business model tools

\footnotetext{
This paper has been derived by the author, from his Master of Science dissertation which was submitted by him to The University of Manchester (and was accepted by the university) towards his aforementioned degree in the year 2017.
}

Prateek Pralhad Kulkarni

hvprateek@gmail.com

1 Goa, India 


\section{Introduction}

\section{Business education in the changing business world}

Business schools across the world run programs that are aimed at offering practical skills and usable knowledge to entrepreneurs, managers, analysts and other people intending or aspiring to take up a business career or advance themselves in their existing roles. It is in a way a unique feature of the business schools which sets them apart from other disciplines and other schools within any university. For example, engineering and other technical schools teach and build upon knowledge which exists, and the new changes or advancements that would come across both the academic research and technical industries are somewhat predicted. This is due to the fact that so much knowledge already exists and the new advancements would be using this knowledge in a new way or making incremental progressions. The only exceptions to these would be the major breakthrough innovations, which do occur, but are slow and also take some time, unless they are well diffused across societies or are well applied/made use of in different industries.

In contrast to these, the business world is different. This is because; so many changes constantly occur and affect the way industries do businesses either in different countries or with various products and services, etc. Also, the changes keep occurring within short spans of time, forcing industries to resort to new strategies or ways of doing their businesses. These changes happen also because of the fact that businesses are deeply intertwined and depend on social, political (and legal), economic and environmental aspects of the regions where they operate, and any changes occurring in these areas have an impact on them, to which they (businesses) have to respond with changes in their strategies, etc. This makes teaching of business courses a slightly difficult task to the business schools and differentiates it from other disciplines. Research and teaching in business schools hence need to constantly keep noticing the changes and innovations happening in firms with respect to their strategies, business model innovations, etc.

\section{Entrepreneurship education, business model tools and experiential learning}

Teaching entrepreneurship is a growing aspect of business schools in some of their degree programs, and also, several business schools across the world have some programs that are wholly dedicated to teaching entrepreneurship and innovation management. Among most of the business courses being taught across universities, business model tools are also being taught along with various other concepts. Hence, both new start-ups and academic business schools rely on the business model tools either for practical use (as in the case of the businesses), or for teaching entrepreneurs and for further research in order to improve business models for both start-ups and established businesses (in the case of academia). This makes business models a topic of interest for experts from both the fields of business and academia. The important factor about the business models 
with regard to the teaching of these in business schools to entrepreneurs is that how could these be made more of an experience to the entrepreneurs, because, although, most business schools teach these with several examples and scenarios of real businesses, entrepreneurs must be able to research the various aspects of the business models for their own start-ups in an appropriate manner. Along with this, they must also acquire the skills of using these tools for innovating new products or services, considering all the aspects of the businesses, instead of just the novelty in the opportunity recognition.

Therefore, it is important to do research on the aspect of 'experiential learning' of the business model tools, which, as defined and used in the papers by Shepherd and Dhliwayo (2008), Ho et al. (2014) and McCarthy and McCarthy (2010), implies that for learning to take place, experiences have to occur or (it also implies) the experience achieved through the practical application of knowledge.

Glass and Freeman (2016) mention 'Current research suggests that college entrepreneurship courses tend to be abstract and lack concrete experiential elements that encompass the total entrepreneurial experience'.

Therefore, bringing the two concepts together of experiential learning of entrepreneurship and the study of business model tools, it is crucial to state that business model tools are a starting point entrepreneur has to rely on and make use of, in order to develop the features of their business ideas. The business model tool in particular being referred to in this paper is Osterwalder's Business model canvas-Strategyzer (2017); and the participants' in-depth elaborations of their ideas corresponding to its sections. It is hence important for students aspiring to be entrepreneurs to obtain a firsthand experience of using the business model tools for their own ideas. The business start-up competition of Venture Further is designed such that its participants have to make use of the business model tools in order to articulate their business ideas to the judges. This research analyses whether the participants of Venture Further 2017, who have been qualified by the judges (judges who assessed the participants' business ideas on the basis of their articulation through the use of these tools), feel that through this exercise had an experiential learning of using these business model tools, thereby seeing the purpose of this competition being served in offering a practical entrepreneurship education with respect to the use of these tools. Also, along with this, it will be investigated as to what factors from the conceptual model of Leung et al. (2012) influenced these students to participate in Venture Further 2017.

\section{Differences between this paper and Leung et al. (2012)}

This paper aims at conducting research to answer some of the questions which have not been considered in Leung et al. (2012). Now, these differences between the research at which this paper is aimed at and the existing research from Leung et al. (2012) will be discussed. Before the major differences are discussed, some of the obvious differences are: 
1. The university being considered: In Leung et al. (2012), the university is based from Hong Kong, but in this paper, University of Manchester is being considered.

2. The number of students being interviewed or surveyed: In Leung et al. (2012), the number of students who were surveyed by questionnaire is large than the number of students who will be interviewed for the research of this paper. The reason for this is because interviewing is the methodology being used and also it is a qualitative research being carried out, which means that there is a need to acquire as much information as possible from a group of people which cannot be large, and then analyse those data in order to know how has been the impact of the business start-up competitions on both the perceptions and also on the experiential learning of using the business model tools. But in Leung et al. (2012), the method being used is questionnaire, with multiple options for the students, and hence, they needed a large sample size.

3. Another important difference is that in Leung et al. (2012), the authors have classed all the entrepreneurial activities under one category, which would not be limited to business start-up competitions alone, but would also include (along with business start-up competitions) other activities like entrepreneurship workshops or campus incubation programs (Leung et al. 2012). Then, an analysis and research are being carried out to understand students' perceptions. But in this paper, the focus is only on the business start-up competition which is annually being held by the University of Manchester for its students and also the graduates.

Now, there will be a discussion on some of the major differences between the research from Leung et al. (2012) and the research from this paper. The first most important difference is the consideration of the students from the business school. Because the students from the business school study about some of the aspects related to entrepreneurship, it is worth investigating as to whether these students do or do not have some of the perceptions about entrepreneurship which students from the non-business disciplines (like engineering students) have.

One of the most important concepts which business school students are taught is the use of business model tools which help them in coming up with some helpful assumptions about the various aspects related to their business ideas. In this regard, the question that arises which this research seeks to answer is did the prior knowledge of the business development tools influence or impact the perception of the business school students with regard to participation in entrepreneurial activities like the business start-up competition of Venture Further 2017? In Leung et al. (2012), the authors' focus is on engineering students, while here, it is on the business school students irrespective of their specializations. So an advantage of the research being carried out in this paper is that comparisons can be made between the perceptions of the business school students (derived from this research) and the perceptions of the students from the non-business discipline of engineering in particular.

Since the authors of Leung et al. (2012) have not identified features or parameters influencing the perceptions of the students they have analysed on the basis of their technical skills or knowledge (since these students are engineering students), one can easily categorize the students being tested in that paper as the students from non-business disciplines and use it, although in reality, the 
validation has been done only upon the engineering students (their data alone are used to support the hypotheses in that paper); under which pretext, it will become eligible to compare the analysis of that paper with this paper. Hence, this comparison will be of the perceptions on participation in entrepreneurial activities of the business school students, on the one hand, who have learned in their course about the business development tools with the non-business school students, on the other hand (taken from the results of Leung et al. (2012); students from other disciplines are not interviewed in this paper), who are unaware of these tools.

The second crucial difference is that of the concept of "experiential learning', which is not included and analysed in Leung et al. (2012). Experiential learning of the entrepreneurial concepts or tools (which in this case are the business model tools) is one of the expectations from the students who participate in on-campus entrepreneurial activity-which for this paper's research is the individual activity of business start-up competition, i.e. Venture Further 2017. This is an important aspect to consider, because it is not just once that the students aspiring entrepreneurship will be using the entrepreneurial tools from the oncampus entrepreneurial competitions they are participating in, but rather, they will have to rely on these tools pretty often, later in their entrepreneurial career, in order to make strategically important decisions pertaining to their business, no matter at whatever stage it might be. Due to this importance, this paper's research is also analysing as to whether the students of the University of Manchester are getting an experiential learning of using the business model tools by participating in the business start-up competition of Venture Further 2017.

Hence, this paper is not just analysing the factors which influence the perceptions of the students that impact their participation intentions in Venture Further 2017 , but also analysing as to whether after participating in this competition, those students who have been shortlisted are feeling more confident of having got an experience of using the business model tools. One of the reasons why this investigation is necessary is because it forms a crucial part of the business start-up competitions, and also, through it, there is a possibility to establish links between the various parameters which are associated with the high entrepreneurial skills of certain students. The students who have been shortlisted for the Venture Further 2017 competition were firstly inspired to participate in it, due to their perceptions about this competition which depended on some of the factors like those mentioned in Leung et al. (2012). They were then required as a part of their participation to research the various aspects about their business ideas and articulate their business ideas in accordance with the various business model tools needed to be used for Venture Further 2017.

The fact that they were then shortlisted by the judges authenticates or validates the notion that they were better able to articulate their business ideas through the use of the business model tools. From participation inspiration to experiential learning of the business model tools, these students were constantly able to maintain an entrepreneurial mindset and worked through the business start-up competition. This will hence be an interesting analysis. 


\section{Development of the research framework}

In this section, the discussion is focused around the research design and explanation of the conceptual framework being presented in Leung et al. (2012) with the proposed contribution of this paper as an extra addition [to the conceptual framework from Leung et al. (2012)]. The proposed hypotheses will also be presented. The following section presents the research triangle and its explanation, before progressing on to the conceptual model and the research hypotheses.

\section{Research triangle}

In order to present the research triangle, the independent and the dependent variables of the research question must be identified. Also, the empirical context needs to be defined which for this paper is the first-round shortlisted candidates of Venture Further 2017. The research triangle of this paper is shown in Fig. 1.

The research questions for this paper can thus be stated as:

Did the students of the University of Manchester who are pursuing a business degree obtain an experiential learning of using the business model tools by participating in Venture Further 2017 competition? This research studies the impact on the students who participated in the Venture Further 2017 competition and have been shortlisted, not on those students who have been rejected.

Did the perceptions towards entrepreneurship identified by Leung et al. (2012) influence the participation intentions (for the competition) of the shortlisted students of Venture Further 2017?

The reason for choosing the University of Manchester is because its business school offers postgraduate programs related to entrepreneurship and innovation management, aimed at assisting both the students interested in pursuing research in entrepreneurship or innovation management and also students aspiring to become successful entrepreneurs. Moreover, the Venture Further business start-up

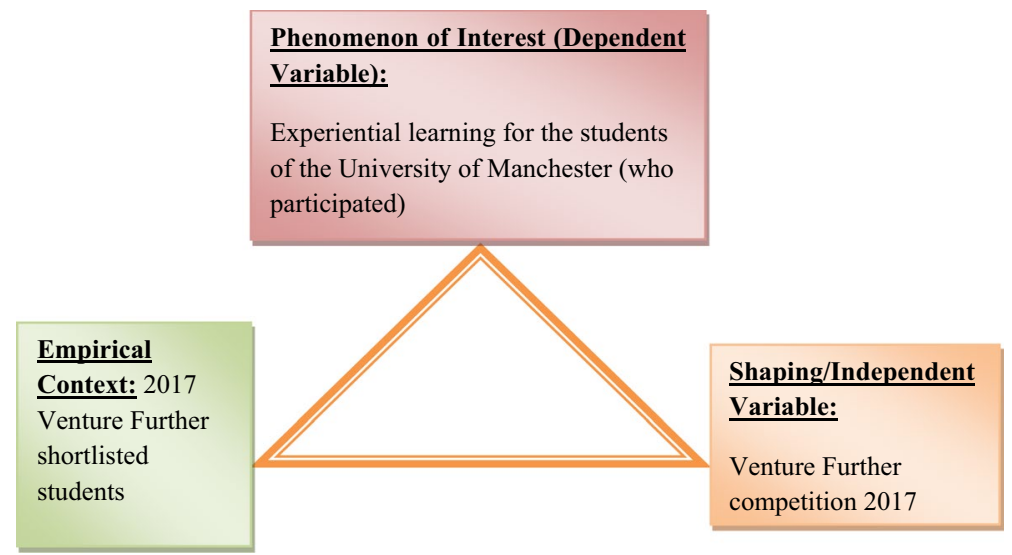

Fig. 1 Research triangle. Source: Researcher's own (2017) 
competition helps in identifying entrepreneurs with commercially feasible business ideas who have also formulated realistic business plans to take their respective business ideas forward. Also, the financial benefit from winning in this competition is the award of GBP 10,000 to the successful candidates, which is quite useful for entrepreneurs (with their start-ups at a very early stage) to invest into their start-ups.

Out of the total number of participants which is 72 for the Venture Further competition 2017, only 16 of the applications have been shortlisted. Hence, out of those 16 students, the business school students are the ones who will be interviewed as the research of this paper focuses on business school students.

\section{Conceptual model}

This section will present the conceptual model on which this research is based. The conceptual model being presented here is borrowed from Leung et al. (2012), and a new factor is added which is of experiential learning of the business model tools by the students who participate in the on-campus entrepreneurial activity of Venture Further.

Considering Fig. 1, Leung et al. (2012), the following hypotheses are proposed from Leung et al. (2012).

H1 Participation of engineering students in the on-campus entrepreneurial activities is related to their participating intentions.

H2 The intention of engineering students to participate in the on-campus entrepreneurial activities is related to their attitude towards entrepreneurship.

H3 The intention of engineering students to participate in on-campus entrepreneurial activities is related to their perceived feasibility to carry out the activities successfully.

H4a-e (a) Need for achievement; (b) locus of control; (c) risk-taking propensity; (d) innovativeness; (e) social network is related to the attitude of students towards entrepreneurship.

H5a-c (a) Gender; (b) role model; (c) start-up experience is related to the attitude of students towards entrepreneurship.

H6 Intention of students to participate in the on-campus entrepreneurial activities is related to their perceived barriers in these activities.

H7 Intention of students to participate in the on-campus entrepreneurial activities is related to their financing concerns.

H8 Intention of students to participate in the on-campus entrepreneurial activities is related to their perceived opportunity costs for participating in these activities. 
Here, the authors of Leung et al. (2012) have considered a number of factors which correspond to the various intentions of the students that influence their participation in the on-campus entrepreneurial activities. In most universities, on-campus entrepreneurial activities are considered as extra-curricular activities. This means that these activities are not looked upon as the main course work for students, and hence, students have a choice to participate in such activities. Thus, the hypothesis can be stated as:

H9 There is a positive relationship between the experiential learning of the business model tools by the students (the shortlisted participants of the on-campus business ideas competition which in our case is Venture Further 2017) and the participation of these students in this on-campus business idea competition.

There could be more factors, which influence students' intentions to participate in on-campus entrepreneurial activities, rather than those that are mentioned in Leung et al. (2012). However, this paper will only focus on whether these factors mentioned in the paper Leung et al. (2012) did influence the students' perceptions towards entrepreneurial activities (Figs. 2, 3, 4).

It is worth mentioning that the candidates who succeeded in the Venture Further competition alone can be considered as having acquired the experiential learning of using the business model tools in contrast to those who were unsuccessful, and hence, this sample has been chosen. The question of whether these students correctly articulated their business ideas through the use of the tools, can be answered by analysing the criteria used by the judging panel to shortlist the candidates. These criteria (from the application process required by the participants for Venture Further 2017) depend on two factors, which are:

1. The efficient articulation by the participant of the various business (model) aspects pertaining to his/her business idea(s).

2. The efficient identification of a unique/new opportunity by the participant for which he/she is offering a solution.

In the case of rejected candidates, either or both of the above factors are not fulfilled. Both of these need entrepreneurs to appropriately make use of business model tools for efficiently starting up their ventures. In contrast to this, the successful candidates (students who have been shortlisted) are those who have efficiently fulfilled both the conditions and are hence shortlisted by the judging panel.

These students have therefore correctly used the business model tools and hence could be assumed to have acquired the experience of efficiently using the business model tools for coming up with business idea(s). They are thus the suitable candidates who can be the interviewees for this research. This could hence be looked upon as an example of concept sampling. From the fact that these candidates have been shortlisted, they can be considered to have acquired the practical skills of using the business model tools, but the interviews will allow to know 


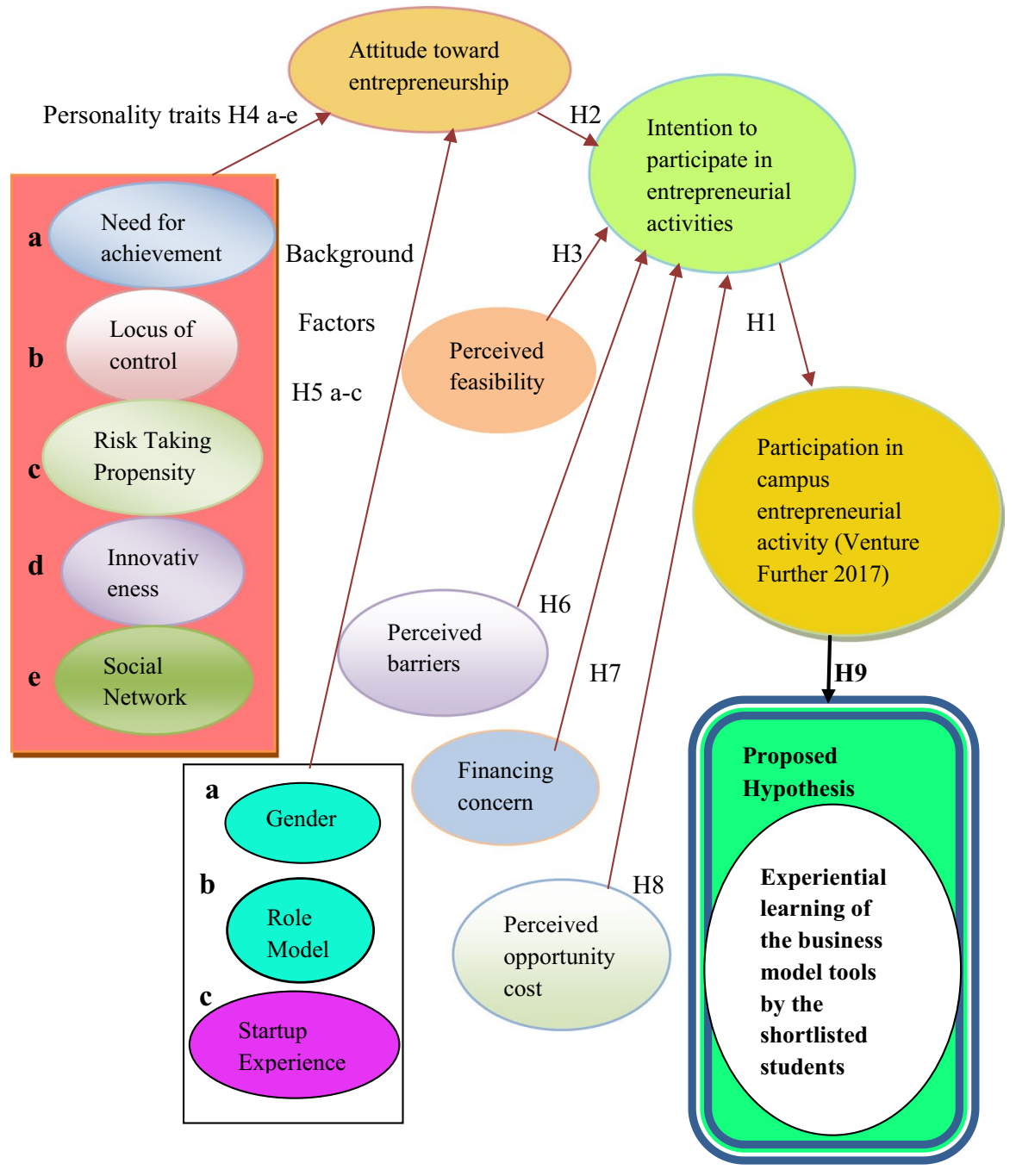

Fig. 2 Conceptual model (adapted from Leung et al. 2012) with proposed hypotheses

from them as to whether they consider their participation in Venture Further 2017 has given them an experiential learning of the business model tools.

\section{Interviews' data analysis and discussion}

This section discusses about the interview responses from the participants. It includes the responses for both sets of questions which the participants were interviewed about, which are the perceptions of entrepreneurship that impacted their intentions and also the questions about experiential learning aspects. 


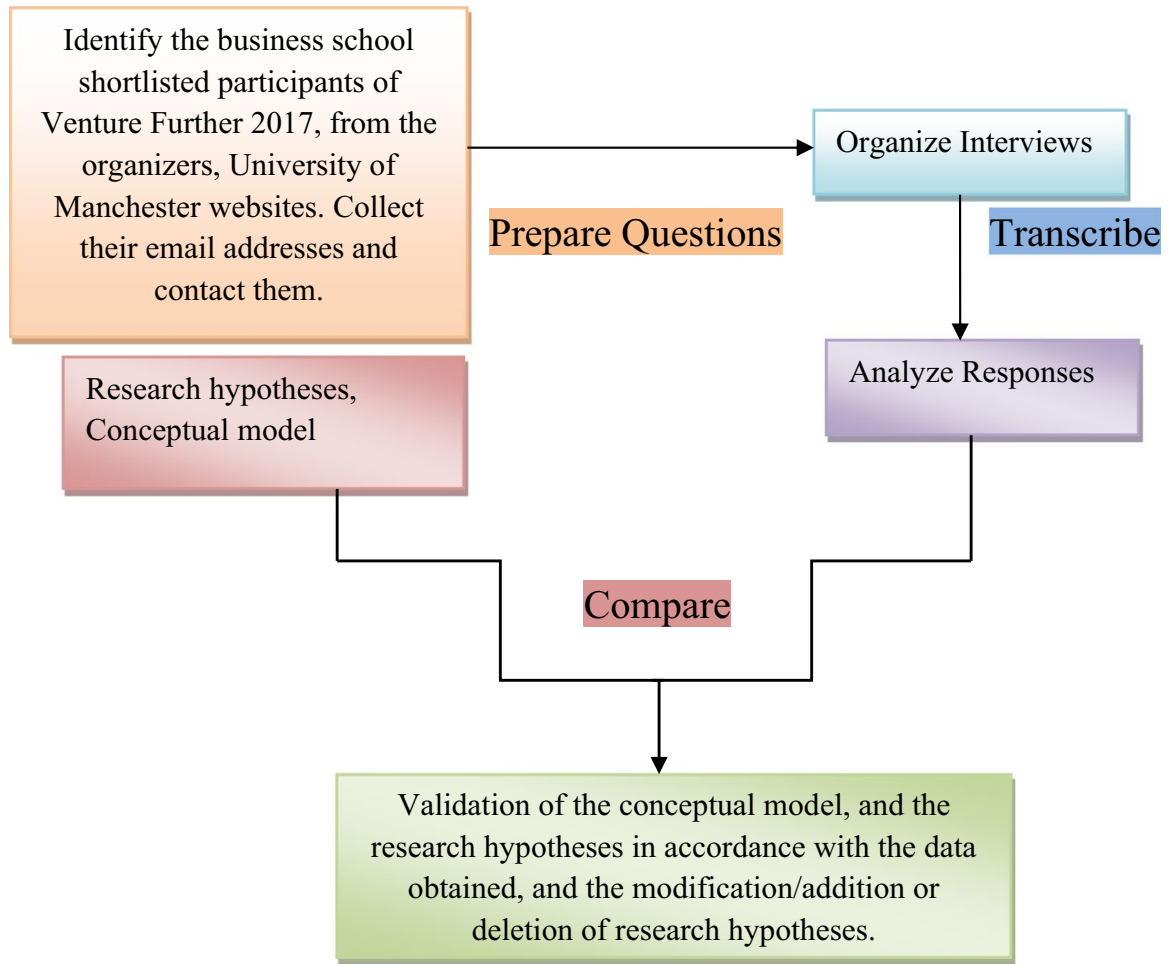

Fig. 3 Block diagram of the methodology for data collection and its analysis for this dissertation. Source: Researcher's own (2017)

\section{Steps for conducting interviews}

Pictorial representation (Fig. 3) shows some of the stages in the process of data collection for this dissertation.

Referring above, the first task is identifying the business school shortlisted students of Venture Further 2017 and from the University of Manchester. Then, these students were requested to participate in interviews.

Eventually, five participants agreed to partake in the interviews. Interviews were conducted; and the data were collected. Then, the data were analysed and were compared with the proposed research hypotheses and also the conceptual model. Validation is done of those hypotheses which are in accordance with the data, and those which are not in accordance with the data are rejected.

It could have been also useful to interview the judges of this competition; however, due to limited time to carry out this research, it cannot be done. Interviews were conducted as per the convenience of the interviewees at their convenient location and time. The names of all the interviewees have been made anonymous. No participant's name is mentioned when referring to his/her data in the dissertation. All of these procedures were followed in order to ensure that the 


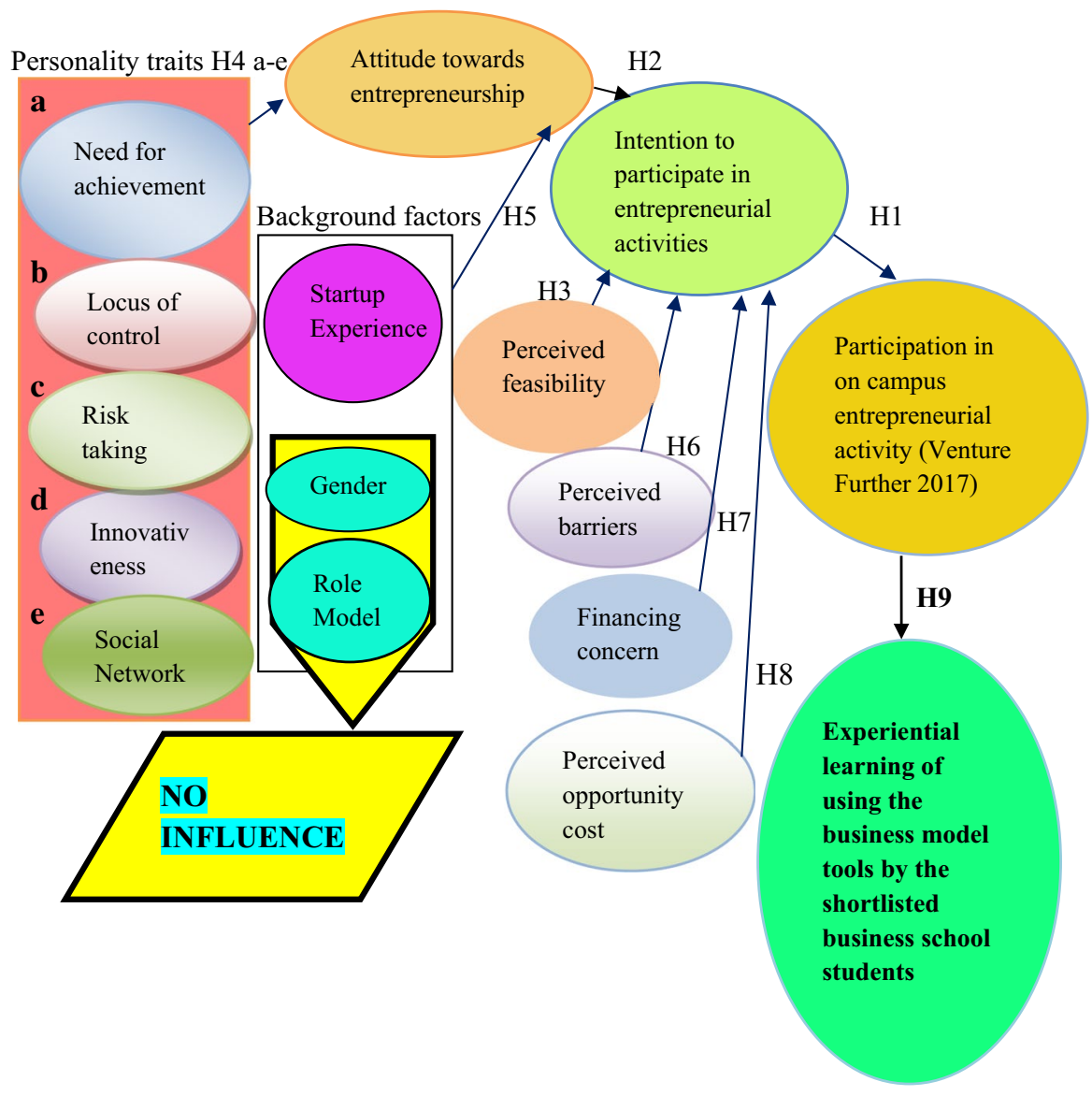

Fig. 4 Conceptual model. Modified from Leung et al. (2012)

confidentiality of the participants' names and personal details is maintained. Once the interviews were completed, the collected data were analysed by logically evaluating the responses of the candidates to answer the main research questions. The similarity in the responses given by the various candidates was analysed to identify the most common factors that influenced the participants' intentions. The identification of these common factors was important as these would form the major component of the answer to the research question. It has been shown from the analysis of the judges' evaluation method that only those participants who have demonstrated the best use of the business model tools and have appropriately articulated their respective business idea(s) through these tools, have been shortlisted. The interviews are now left to confirm this from the viewpoint of the students, as to whether they consider their participation in Venture Further as an exercise of gaining an experiential learning of using the business model tools. 
Also, since the gender of each of the participants must not be disclosed, while discussing about each of the participant 'he/she' or 'she/he' will be used to refer to the corresponding participant, as and where such usage may be required.

\section{Structure of interview questions}

The interview questions were categorized into two parts: The first one is, being questions directly asking Venture Further 2017 winners, whether factors from H1-H8 impacted them? This would be a testing of the hypotheses from Leung et al. (2012) with Venture Further 2017 winners. The next section of the interview questionnaire was of experiential learning of business model tools by these participants. Here, there were two questions asked to these winners:

1. With the inspiration to win in this competition (and be advantaged by the money award of GBP 10,000 to invest into the business) and the necessity of using business model tools in order to participate in this competition (as a mandatory requirement to demonstrate the aspects of your business idea), do you feel that you had a complete experience of fully understanding the use of business model tools? Did this competition prove to have provided a unique experience of applying the business model tools to you? Was this experience better than the classroom experience of learning the business model tools?

2. Did your learning of business model tools in the class help you better articulate your business idea(s) in this competition? (because you had started analysing your business idea(s) from the perspective of the business model tools that were taught to you in the classroom)

These questions helped analyse the new hypotheses being presented in this research about experiential learning of the business model tools, by the winners.

\section{Interpretation of the interview results}

In this section, the analysis of the interview responses will be done. Each participant's response to the three questions will be discussed, the data findings of which can be used in the next section for deriving the results.

\section{Participant A}

Perceptions on entrepreneurship that impacted the intention to participate For the impact of 'Attitude towards Entrepreneurship' on the participating intentions, the participant feels that his/her intentions to participate were irrespective as he/she would definitely participate in Venture Further. The participant was also confident about the feasibility and the strengths of his/her business idea. He/she considers the requirement to get funding for his/her business idea as one of the biggest barriers, and this also drove the participant into participating. He/she found a huge workload for the application process into the competition, which would take quite some time from his/ 
her academic program; however, the confidence was high in this participant of winning or being shortlisted, and hence, 'opportunity cost' did not severely impact. The participant wanted to achieve success in this competition by winning the money and the award.

Experiential learning of the business model tools and other responses With regard to the experiential learning of using the business model tools, this participant agreed to have had an experiential learning of using the business model tools due to the requirement to use these in the application process (of competition). Moreover, she/ he also found that this experience and the learning due to it were much better than the learning experience of using the business model tools in the classroom. He/she also believes that the more load of work involved, to articulate one's business idea to a panel of judges, the more is the learning acquired out of it, which was the case with the competition. He/she understood the intention of the organizers of the Venture Further competition in keeping such requirements for the competition, which makes participants work hard and more than mere elaboration of the business ideas. He/she believes that the pitching process was the most unique of this competition to have offered an experiential learning. It was due to the extensive preparation the participant did for creating the business articulation content that not only was this content used for Venture Further 2017, but she/he could use the same content with very few modifications in other start-up competitions. This proves that the pitch deck aspect of Venture Further competition requires from the participants to cover each and every aspect of their business ideas. And the various sections of the pitch deck are nothing but the business model tools that are used for articulating the business ideas. It hence proves that participants need to work rigorously using the business model tools, to articulate their business ideas, and participant $\mathrm{A}$ felt that this was an important experience demanding proper efforts. It is hence clear that participant A had an experiential learning of using the business model tools.

\section{Participant B}

Perceptions on entrepreneurship that impacted the intention to participate This participant wanted to experience entrepreneurship within the framework of Venture Further (not a business idea competition in general, but specifically Venture Further 2017), which impacted his/her intention from the perspective of 'Attitude towards Entrepreneurship' to participate in Venture Further. His/her track record of winning start-up competitions has improved his/her confidence in the success of his/her business idea(s). This affirmed him/her about the feasibility of his/her business idea(s) for participating in the competition. With regard to the perceived barriers having impact on the intention to participate, he/she sees that by participating, he/she could better understand the risks associated with his/her business idea(s), and hence sees participation as means of de-risking the risks assumed about his/her business idea(s) and also values the outcome of being able to assess his/her position (with the start-up) from the success in this competition. With regard to the 'Opportunity cost' involved with the participation in this competition, this participant feels that there was no loss of time and efforts (which would have been towards the academic work, was there 
no need to participate) by participating in this competition and it rather added more value to his/her academic work. This participant also believes that his/her previous start-up experience did impact positively his/her intention to participate. Also, the participant feels that his/her need for achievement was an important driver in his/her intention to participate as he/she does not intent to work for someone.

Experiential learning of the business model tools and other responses This participant feels that he/she 'very much' had an experiential learning of using the business model tools, by participating in Venture Further 2017. One of the reasons for this, as he/she says, is because of the way it was structured, forcing him/her to cover all the aspects of his/her business, and it also helped him/her in identifying areas which he/she had not addressed (he/she refers to them as 'gaps') of his/her business before. This experiential learning also helped him/her by increasing his/her confidence in overcoming difficulties related to business models. By participating in Venture Further 2017, he/she also had to test whether the value being offered was unique when compared with the existing solutions being offered to the same problem. The participant also values the feedback and the comments he/she got from the judges of this competition. It was also responsible for boosting the confidence of the participant in his/her business idea(s). (This participant has won in two categories.)

In terms of offering a unique experience, the participant feels that this competition was not very unique as the participant has participated previously in similar competitions. This is also a crucial aspect. The participant's previous participations and successes in business start-up and/or business ideas competitions, not only increased his/her confidence but also gave him/her a practice of working for such tough and practical competitive environments eventually making him/her fearless and motivated to participate in such competitions in the future. This is an effect of the experiential learning acquired by the participant's previous successes in such competitions.

With regard to the classroom experience of using the business model tools, the participant feels that indeed the experience from the competition was much better and more valuable than the classroom experience of using these tools. The participant points out some genuine reasons that support this argument. The participant mentions that privileges like prestige, money and other incentives are not available for the students from the classroom teaching being offered. On the contrary, by participating and winning in Venture Further (students who have won) they are able to enjoy prestige, money, valuable feedback (from judges), etc. Another reason pointed put by the participant is that in classroom teaching, business model tools are not taught with respect to individual student's business idea, but rather having these applied to others' business ideas, case studies, etc., which also may not contribute to the effective participation and earning by the students of these tools. This is not the case with the competition.

The participant does not feel that the classroom teaching of the business model tools helped him/her by easing the efforts for participating in the competition. This is because the participant has had participation experiences in competitions similar to Venture Further in the past, and hence used business model tools before in such instances. He/she was therefore 'pre-prepared' with 'more knowledge' and 
application of business model tools to his/her business ideas. Therefore, the learning of using the business model tools in the degree program of participant B was not new or first-time learning.

\section{Participant C}

Perceptions on entrepreneurship that impacted the intention to participate This participant did find that the participation process for Venture Further involved a lot of work. He/she feels that one needs the right attitude and the right drive to participate in any business competition. With regard to perceived barriers to the business start-up having impact on the intention to participate, this participant feels that he/she would see obstacles as opportunities to exercise his/her entrepreneurial skill sets. Also, he/ she had prioritized the application towards the participation in Venture Further before his commitments and work towards his academic degree. He/she also aspired to win the money award in order to invest and also get interest in his/her business. Here, it appears that being shortlisted in Venture Further had an inspirational effect towards entrepreneurship in this participant. Also, this participant's previous entrepreneurial experience had a positive impact on him/her as he/she learned from this experience the need to participate in competitions like Venture Further.

Experiential learning of the business model tools and other responses Participant $\mathrm{C}$ expresses that he/she has learned more about the business model tools and better understood as to how to use certain parts of the business models, which could be essential. The participant feels that looking as a whole he/she has been through a better learning experience by participating in Venture Further competition. With regard to learning-specific aspects of the business models in detail, the participant mentions about being through an in-depth learning of performing financial analysis for the business and how to calculate and use financial parameters related to business, etc. This is in accordance with what has previously been mentioned in this paper; that is, entrepreneurs generally tend to prepare themselves efficiently only in the value proposition they are offering which could be within a field of their interest and may tend to neglect other aspects pertaining to their ideas, which are important from a business perspective.

The participant mentions that participating in the Venture Further competition offered him/her with a unique experience as it was specifically addressing his/her business idea, but in general, the experience of using these tools was not unique. This is because the participant has learned using these tools in the classroom, applying them for other business ideas. Moreover, the participant found a number of other benefits of participating and winning in this competition. These are the award of money, the networking opportunities with experts and entrepreneurs and also the feedback from experienced judges. To add to this, the participant also felt that his/ her presentation skills were improved and he/she also learned how to present business start-up plan in front of potential investors.

When comparing classroom learning experience with the experience acquired by participating in Venture Further 2017, the participant feels that classroom experience is less useful due to it being theoretical, its dependence on group work and 
lacking motivation. The competition, on the contrary, was a real-life experience according to the participant, and it was valuable and better.

With regard to classroom teaching of the business model tools having an impact of easing the participant's efforts for the competition, the participant feels that not necessarily this was the case. While the classroom learning did expose the participant to business model tools, it was not until his/her participation into the competition that he/she learned how to analyse specific sections of the business models for the business idea. Hence, the participant had not analysed specific sections of the business models he/she had learned, and hence, it was only during the competition this opportunity came. So the participant feels that if a proper analysis of the business idea with the help of the business model tools has to be done, then it is the competition, where students are required to do this. Also, the participant feels that the students must come up with their own business models and similar tools for developing aspects related to their business ideas, rather than relying on the use of the standard tools.

\section{Participant D}

Perceptions on entrepreneurship that impacted the intention to participate This participant has been an entrepreneur before and has experience of entrepreneurship and therefore feels that his/her attitude towards entrepreneurship from this experience greatly impacted his/her intention to participate in this competition.

$\mathrm{He} / \mathrm{she}$ had received backing from his/her colleagues about the viability of his/ her business idea with which he/she wanted to participate in this competition. As a result, this participant was positively impacted by his/her perception about the feasibility of his/her business idea for participation in this competition. Similar to the opinion of Participant B, even this participant felt that by participating and succeeding in this competition, he/she could learn to overcome some of the obstacles he/ she may have initially perceived about his/her business idea. This belief was the participant's one of the expected outcomes of participation in this competition. Also, this participant experienced strong support from peers in order to participate in this competition and devote some of the time and efforts of his/her academic program into the participation process for the competition. Like all the previous participants, this participant also needed the money from the award. Moreover, the participant strongly expressed that his/her previous entrepreneurial experience and also most importantly his/her previous experience in participating and winning in business idea/start-up competitions, impacted his/her intention to participate in Venture Further. With regard to the personality traits of this participant, he/she felt that due to his/her belief in hard work and effectiveness (locus of control) was impacted to participate. He/she also felt that his/her risk-taking attitude has been strengthened by his/her experiences of successes and failures in entrepreneurship and his interest in social networking; both had a positive impact on his/her intention to participate in Venture Further.

Experiential learning of the business model tools and other responses This participant did feel that he/she had some experiential learning by participating in Venture 
Further. But he/she feels that this experience was not a unique experience. One of the reasons for this is because this participant had participated in Venture Further in the previous year also, and it was then when this participant felt that he/she had an experiential learning of using the business model tools, but not during this year's participation.

Also, this participant expressed that for his business team member this participation was indeed a unique experience as he/she had participated for the first time in Venture Further.

This participant has an experience of participating in such business start-up competitions, prior to coming to the business school. She/he not only has experience of working for his own start-ups as he has been an entrepreneur before, but he/she also has good experience of participating and often winning in business start-up competitions. This is one of the important aspects of this participant. She/he has also pitched his/her ideas to investors before and has learned how to pitch and acquired skills from such opportunities in the past. Moreover, this participant mentions that she/he does not have a classroom learning experience of using the business model tools, unlike what it is for the Master of Enterprise students who participated in Venture Further 2017 participants. Hence, the participant has self-trained himself/ herself in using the business model tools and also mentions that has practiced them for his business ideas.

Although this participant did not have a classroom experience of using the business model tools, he/she has taken short courses in the past, which have taught him/ her as to how to use business model tools. The participant practiced using the taught business model tools in such short courses on entrepreneurship to his/her business ideas. This greatly helped the participant in working for his/her business and participating in various competitions back then, and this experience is also helping him/ her now with such opportunities. Moreover, the participant mentions that he/she did not depend upon the tools entirely, but rather practiced using some of these tools for his/her own business ideas in the past. The participant also says that one has to be very comprehensive by properly explaining all the aspects of his/her business ideas. According to the participant, the pitching process is similar to trying to actually sell products to the customers. The participant mentions that he/she in way had to 'sell' his pitch to the judges. She/he therefore feels that one has to be very comprehensive in articulating aspects his/her business idea(s) in competitions like Venture Further.

\section{Participant E}

Perceptions on entrepreneurship that impacted the intention to participate This participant expressed that his/her attitude towards entrepreneurship was one of the main drivers for his/her competition. The previous success of this participant's business idea in Venture Out gave him/her the optimism that it is a feasible business idea, which in turn inspired him/her to participate in Venture Further. This participant also was aware of the problems/barriers he/she was facing with regard to his/her business idea, and therefore, these barriers did not influence him/her from participating in Venture Further. Moreover, with regard to the opportunity cost involved with the participation in Venture Further, this participant felt that due to the similar kind of 
practical learning activities he/she was going through in his/her MBA program, he/ she was able to devote some of his/her academic time towards the participation process for this competition, as he/she felt that it was like opting for a course very much aligned to what he/she was already studying. And again, like all the other interviewed participants, even this participant was positively influenced by the financing concern for his/her start-up. He/she was highly motivated due to the monetary award from this competition, and that was his/her main objective, as he/she puts it. He/she was also inspired by the success in Venture Out and wanted to win in Venture Further as well. Also, this participant considers his/her success in Venture Out itself as his/her previous start-up experience. Moreover, this participant was also impacted positively by his/her aspiration to win GBP 10,000, his/her risk-taking propensity and his/her belief in the need for social networking, to participate in Venture Further.

Experiential learning of the business model tools and other responses This participant also admitted to having had an experiential learning of using the business model tools by participating in Venture Further 2017. The participant expresses how important are the business model tools, due to their help in visualizing one's business idea, how they also assist in identifying the missing aspects of the business plan, etc. But the experience of pitching in this competition of Venture Further 2017 is not a unique experience for this participant (as the participant mentions) since he/she had a similar subject in his/her MBA program at the University of Manchester.

This participant mentions that he/she had opted for a particular elective subject in his/her MBA program, which required students to work in groups to come up with a new business idea and prepare a plan to pitch it in front of investors. It was here that the participant mentions to have acquired a unique experience of learning how to pitch in front of potential investors for possible investments. Hence, the pitching process in Venture Further 2017 was not a unique first-time experience to this participant. Moreover, the participant had gained confidence by working through that particular subject in his/her MBA program, which in a way eased the same process (of presenting a pitch in front of experts) in his/her participation at the Venture Further.

With regard to using the business model tools for business ideas, this participant was not exposed or taught the use of business model tools in his/her MBA program. The competition hence proved to offer a unique experience and learning of using the business model tools, according to the participant. More importantly, this competition was hence a source of learning of the use of business model tools. The participant had not only to learn the use of these tools, but also use them for his/her business idea, so that he/she could pitch it in front of experts. Also, this participant deeply values the feedback he/she received from the judges about his/her business idea, as it greatly helped. For example, the participants mention that one of the judges of Venture Further explained to this participant, as to how he sees this participant's new offering and most importantly, how this participant must design its branding to obtain maximum customer attention. 


\section{Data evaluation with respect to the proposed hypotheses}

This section will discuss the results of the data analysis. The conceptual model that has been presented in Leung et al. (2012) was modified, new hypothesis was proposed, and added to it, based on which, research questions were framed. Comparison will now be done, with the data to establish whether the hypothesis is true or not. Moreover, new results which have come to light from the data analysis, but were not proposed, will also be presented here.

From the results of the interviews and the analysis of the data, the hypothesis that "There is a positive relationship between the "Experiential learning" of the business model tools by the business school students (the shortlisted participants of the on-campus business ideas competition which in our case is Venture Further 2017) and the participation of these students in this on-campus business idea competition' has proved to be valid and is hence accepted. This also answers the first research question that was taken up and has been mentioned in the 'Development of Research Framework' section. The answer to that research question is yes; the shortlisted business school participants of Venture Further 2017 had an experiential learning of the use of business model tools. As for the second question, which deals with the perceptions of entrepreneurship, that may have impacted the intention to participate of the participants, the data analysis proves that some perceptions did while some did not. The ones that did not impact were 'gender' and 'role model', because for these two parameters, most participants' (four or more out of five) response was 'no'. All other parameters did impact the perceptions of the participants.

\section{Direct experiential learning for some students}

A new aspect that has come to light from this research is the possibility of learning new knowledge for some of the shortlisted candidates within the business school through this competition of Venture Further. For example, Participant $\mathrm{C}$ and Participant $\mathrm{E}$ could be considered. Participant $\mathrm{C}$ is from a program on entrepreneurship, but Participant $\mathrm{E}$ is from MBA program. Participant $\mathrm{E}$ had not learned the business model tools in his/her course. But by participating and being shortlisted in Venture Further, he/she not only got exposed to business model tools, but also had an experiential learning of using these tools. He/she, however, had a thorough experience of pitching in front of investors, which was taught to him/her in one of the elective subjects he/she had chosen in the MBA program. Participant C, on the other hand, had studied business model tools in his/her non-MBA program focused on entrepreneurship. But he/she had no knowledge and experience of pitching in front of investors, which he/she got an opportunity to learn from his/her participation in Venture Further. Also, Participant A is from the same program as Participant C, and he/she also had the opportunity to experience the pitching process through this competition.

It is also important to mention that the future research must look into what are the effects of previous business start-up participation and success experience in the intention to participate in business start-up competitions among the shortlisted participants who have such experience? This can be taken up as a future research study. This is one of the most crucial questions not analysed in this research. 


\section{Comparison between business students' perceptions and non-business students' perceptions}

From this research, it is clear that the perceptions which affected the intentions of the engineering students to participate in on-campus entrepreneurial activities have also affected (the same perceptions) the Venture Further 2017 shortlisted business school students of The University of Manchester. This shows that most students are influenced by these perceptions. Hence, the future research must focus on specific perceptions of the students with respect to their respective areas of interest for entrepreneurship. For example, engineering students may be having specific perceptions about entrepreneurship from the perspective of certain technical aspects. Such perceptions may therefore be having impact upon their intentions to participate in entrepreneurial activities. Similarly, students aspiring for entrepreneurship from life sciences field may have specific perceptions about entrepreneurship which may be from the perspective of their expertise in life sciences, which could have impact on their intentions to participate in entrepreneurial activities. Such perceptions would be different for people aspiring entrepreneurship in different fields based on the conditions of knowledge and opportunities in those fields being considered.

\section{Modified diagram of the conceptual model}

In this section, the validated theoretical model is being presented, after all the modifications including some results.

\section{Conclusion}

The primary aim of this paper's research was to prove that the shortlisted students of Venture Further 2017 competition from the business school (of the University of Manchester) had an experiential learning of using the business model tools through their participation in that competition. This research can be categorized under a new broad category of 'experiential learning of entrepreneurial tools by students from their participation in on-campus entrepreneurial activities'. There has been no work on this topic prior to this paper. Research exists on experiential learning in business education, but no work has been done on experiential learning about specific entrepreneurial and other business tools in business education. This paper's work is therefore the first of its kind. The study, interviews and the analysis done in this paper prove that there is indeed a positive connection between the experiential learning of the business model tools by the shortlisted students and their participation in Venture Further competition, which implies that these students did have an experiential learning of using these tools, from their participation. These results have also paved ways for further research investigations in the areas of entrepreneurship and business education.

This paper also investigated as to what perceptions of entrepreneurship (identified from the paper Leung et al. (2012)) impacted these students' intentions to participate in Venture Further 2017. Here, the research found that the background factors 
of gender and role model Leung et al. (2012) had no impact on the intentions of the students to participate in Venture Further 2017, but all other factors did impact the participants' intentions.

Open Access This article is distributed under the terms of the Creative Commons Attribution 4.0 International License (http://creativecommons.org/licenses/by/4.0/), which permits unrestricted use, distribution, and reproduction in any medium, provided you give appropriate credit to the original author(s) and the source, provide a link to the Creative Commons license, and indicate if changes were made.

\section{References}

Dhliwayo, S. (2008). Experiential learning in entrepreneurship education: A prospective model for South African tertiary institutions. Education + Training, 50(4), 329-340.

Glass, D. W. \& Freeman, E. W. (2016) The efficacy of a model rubric to enhance experiential learning in an entrepreneurship course: A case study. [Online]. http://digitalcommons.georgiasouthern.edu/ sotlcommons/SoTL/2016/59/. Accessed 7 Aug 2017.

Ho, Y.-P., Low, P.-C., \& Wong, P.-K. (2014). Do university entrepreneurship programs influence students' entrepreneurial behavior? An empirical analysis of university students in Singapore. In: Innovative pathways for university entrepreneurship in the 21st century advances in the study of entrepreneurship, innovation and economic growth (Vol. 24 pp. 65-87).

Leung, K.-Y., Lo, C.-T., Sun, H., \& Wong, K.-F. (2012). Factors influencing engineering students' intention to participate in on-campus entrepreneurial activities. Journal of Entrepreneurship Education, $15,1-19$.

McCarthy, P. R., \& McCarthy, H. M. (2010). When case studies are not enough: Integrating experiential learning into business curricula. Journal of Education for Business, 81(4), 201-204.

Strategyzer. (2017) Business model canvas [online]. https://strategyzer.com/canvas/business-model-canva s. Accessed 7 Aug 2017.

Publisher's Note Springer Nature remains neutral with regard to jurisdictional claims in published maps and institutional affiliations. 